\title{
Effect of Paris saponin I on radiosensitivity in a gefitinib-resistant lung adenocarcinoma cell line
}

\author{
HAO JIANG $^{1 *}$, PENGJUN ZHAO ${ }^{2 *}$, JIANGUO FENG ${ }^{3}$, DAN SU $^{3}$ and SHENGLIN MA ${ }^{4}$ \\ ${ }^{1}$ Department of Oncology, Zhejiang Hospital, Hangzhou, Zhejiang 310013; ${ }^{2}$ Department of Radiation Oncology, \\ Hangzhou Cancer Hospital, Hangzhou, Zhejiang 310002; ${ }^{3}$ Department of Oncology, Zhejiang Cancer Hospital, Hangzhou, \\ Zhejiang 310022; ${ }^{4}$ Department of Oncology, Hangzhou First People's Hospital, Hangzhou, Zhejiang 310006, P.R. China
}

Received September 12, 2013; Accepted February 26, 2014

DOI: $10.3892 / 01.2014 .2020$

\begin{abstract}
Previous studies have observed that Paris saponin I (PSI) exerts a wide range of pharmacological activities, including cytotoxic activity against a number of malignancies, such as non-small cell lung cancers. The present study aimed to investigate the radiosensitization of PSI treatment on a gefitinib-resistant lung adenocarcinoma cell line, PC-9-ZD, and its possible mechanism. A 3-(4,5-dimethylthiazol-2-yl)-2,5-diphenyl-tetrazolium bromide assay was used to determine the growth inhibition effect of PSI. A clonogenic assay was performed to determine the radiosensitizing effect of PSI treatment on the PC-9-ZD cell line. A single-hit multi-target model was used to plot survival curves and calculate sensitizing enhancement ratios. The cell cycle was analyzed by flow cytometry and cell apoptosis was analyzed with fluorescein-isothiocyanate-Annexin V/propidium iodide and Hoechst staining. The expression levels of the proteins were detected by western blotting. There was a significant reduction observed in the proliferation of the PC-9-ZD cell lines that were treated with PSI. PSI enhanced the radiosensitivity of the PC-9-ZD cells with a sensitization enhancement ratio of 1.77. Furthermore, PSI induced G2/M arrest and apoptosis of the irradiated PC-9-ZD cells. Notably, B-cell lymphoma 2 (Bcl-2) was downregulated, and caspase-3, Bcl-2-like protein 4 (Bax) and cyclin-dependent kinase inhibitor $1\left(\mathrm{P} 21^{\text {wafl/cipl }}\right)$ were upregulated by the PSI treatment. The present study showed that PSI treatment exhibited potent radiosensitivity against gefitinib-resistant PC-9-ZD cells in vitro. This radiosensitivity was associated with cell cycle arrest at the G2/M phase, and apoptosis via an increase in caspase-3, Bax and $\mathrm{P} 21^{\text {wafl/cipl }}$ as well as a decrease in $\mathrm{Bcl}-2$ production.
\end{abstract}

Correspondence to: Dr Shenglin Ma, Department of Oncology, Hangzhou First People's Hospital, 261 Huansha Road, Hangzhou, Zhejiang 310006, P.R. China

E-mail: mashenglin@medmail.com.cn

*Contributed equally

Key words: radiosensitivity, clonogenic cell survival, Paris saponin I, gefitinib resistance

\section{Introduction}

Lung cancer has become one of the leading causes of cancer-related mortality worldwide and non-small cell lung cancer (NSCLC) represents $80 \%$ of lung cancers $(1,2)$. The epidermal growth factor (EGFR) is a significant therapeutic target in NSCLC (3). Individuals with somatic mutations of the kinase domain of EGFR often respond to tyrosine kinase inhibitor (TKI) therapy, however, usually exhibit progressive disease following 6-8 months of therapy $(4,5)$. Radiotherapy is extremely important for patients with NSCLC who are not eligible for surgery and patients that have experienced chemotherapy or TKI therapy failure. However, NSCLC cells are generally less sensitive to radiotherapy compared with SCLC cells, which results in radiotherapy failure (6). Although radiotherapy with increased irradiation dosage may delay tumor development, it leads to serious side-effects, including irradiation pneumonitis and a repressed hemopoietic system. Therefore, it is significant to use radiosensitizers to raise the therapeutic effect at a normal irradiation dosage. In the last few decades, increased attention has been focused on identifying biologically active cancer therapeutic agents derived from natural resources (7).

Rhizoma paridis is the root of Paris polyphylla Smith var. chinensis (Franch) Hara and Paris polyphylla Smith var. yunnanensis (Franch) Hand-Mazz. Preclinical studies have shown that Paris saponins (PS) have emerged as promising anticancer agents (8-12), and PSI exerts a wide range of pharmacological activities, including cytotoxic activity against certain malignancies, such as NSCLC (13-17). Therefore, PSI has been approved for cancer therapy due to its potential involvement in the suppression of tumor growth. However, PSI inhibition of signaling pathways and its radiosensitization in NSCLC-TKI resistance has not been identified. The present study focused on examining the radiosensitization effects of PSI on NSCLCs with acquired gefitinib resistance in vitro and to further verify the possible mechanisms.

\section{Materials and methods}

Drugs and reagents. PSI $\left(\mathrm{C}_{44} \mathrm{H}_{70} \mathrm{O}_{16}\right)$ was obtained from Zhejiang Meidikang Ltd. (Zhejiang, China) and the structure of the compound is shown in Fig. 1. PSI was prepared as a 
20-mmol/1 stock in dimethyl sulfoxide (DMSO) and stored at $-20^{\circ} \mathrm{C}$. PSI was diluted with cell culture medium to concentrations of $0.5,1.0,2.0,3.0,4.0,5.0,6.0,7.0,8.0$ and $9.0 \mu \mathrm{g} / \mathrm{ml}$, with a final DMSO concentration of $0.25 \%$ (v/v). Dulbecco's modified Eagle's medium (DMEM) was purchased from Gibco-BRL (Carlsbad, CA, USA), the Cycle Test ${ }^{\mathrm{TM}}$ Plus DNA reagent and Annexin V-FITC \& Propidium Iodide (PI) Apoptosis Detection kits were obtained from Becton Dickinson and Co., (Franklin Lakes, NJ, USA), Hoechst 33258 was purchased from BYT Co., (Nanjing, China), mouse and rabbit antibodies against caspase-3, Bcl-2-like protein 4 (Bax), B-cell lymphoma 2 (Bcl-2) and cyclin-dependent kinase inhibitor 1 (P21 $\left.1^{\text {wafl/cipl }}\right)$ were obtained from Cell Signaling Technology (Danvers, MA, USA) and $\beta$-actin from Santa Cruz Biotechnology, Inc., (Santa Cruz, CA, USA). This study was approved by the Ethics Committee of Zhejiang Hospital and was performed according to the Declaration of Helsinki. Written informed consent was obtained from the family of the patients.

Cell culture. PC-9-ZD (18), an NSCLC cell line resistant to gefitinib following long-term exposure to the drug, was obtained from the Laboratory of Biochemistry and Molecular Biology, Tongji University (Shanghai, China). The PC-9-ZD cells were grown in DMEM supplemented with $10 \%$ fetal bovine serum, $100 \mu \mathrm{g} / \mathrm{ml}$ penicillin and $100 \mu \mathrm{g} / \mathrm{ml}$ streptomycin at $37^{\circ} \mathrm{C}$ in a $5 \% \mathrm{CO}_{2}$ humidified atmosphere.

Cell proliferation assay. The cell proliferation assays were performed using the MTT method, according to the manufacturer's instructions. The cells were seeded in 96-well plates (Costar; Corning Life Sciences, Cambridge, MA, USA) with 5,000 cells/well. Subsequent to an overnight incubation, triplicate wells were treated with various concentrations of PSI for $24 \mathrm{~h}$. Following this, $20-\mu \mathrm{l}$ MTT solutions $(5 \mathrm{mg} / \mathrm{ml}$ in phosphate-buffered saline; PBS) were added to each well and incubated for $4 \mathrm{~h}$ at $37^{\circ} \mathrm{C}$. The MTT formazan was dissolved in $150 \mu$ l DMSO and the absorbance was measured with a microplate reader (Multiskan MK3; Thermo Labsystem, Waltham, MA, USA) at a wavelength of $570 \mathrm{~nm}$. The drug-cell inhibition curve used the drug concentration as the abscissa axis and the inhibition ratio of the drug as the vertical axis. The 50\% growth inhibition $\left(\mathrm{IC}_{50}\right)$ was subsequently calculated according to the curve.

Determination of cell radiosensitivity. The growing cells were exposed to PSI with a concentration of $20 \%$ of the $\mathrm{IC}_{50}$ for $3 \mathrm{~h}$, and irradiated at $0,1,2,4,6,8$ or $10 \mathrm{~Gy}$ with a $6-\mathrm{MV}$ $\mathrm{X}$-ray. After $24 \mathrm{~h}$, the cells were trypsinized, counted and seeded at various dilutions according to the irradiation dose and cultured for 14 days; the colonies were fixed, stained with crystal violet and counted. Only the colonies containing 50 cells were scored and the experiments were performed in triplicate. The cell-survival curve used the irradiation dosage as the abscissa axis and the survival fraction (SF) as the vertical axis. The average lethal dosage of cells $\left(\mathrm{D}_{0}\right)$ and the quasi-field dosage (Dq), which indicates the repair ability of cells to sublethal injury, and extrapolation number $(\mathrm{N})$ values were calculated according to the curve. The sensitization enhancement ratio (SER) was calculated according to the following equations: $\mathrm{SF}=1-\left(1-\exp \left[-\mathrm{D} / \mathrm{D}_{0}\right]\right)^{\mathrm{N}} ; \mathrm{Dq}=\operatorname{InN} /\left(1 / \mathrm{D}_{0}\right)$; and $\mathrm{SER}=$ control group $\mathrm{D}_{0}$ value/treatment group $\mathrm{D}_{0}$ value.

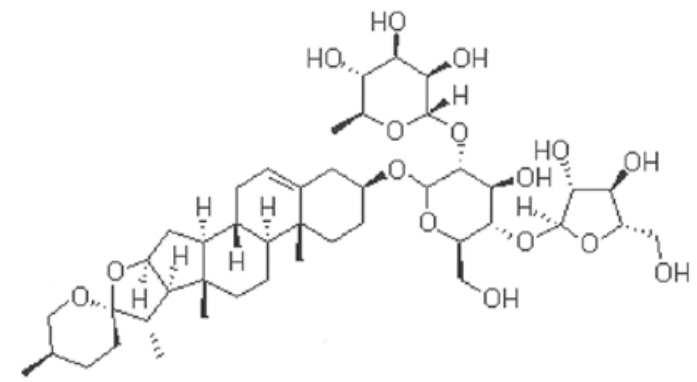

Figure 1. Chemical structure of Paris saponin I.

Cell-cycle distribution. The experimental groups were the control, radiation and PSI + radiation groups. The radiation group received a 2-Gy treatment and the PSI + radiation group received a 2-Gy and a PSI treatment using a concentration that was $20 \%$ of the $\mathrm{IC}_{50}$. Cells were harvested at 12,24 and $48 \mathrm{~h}$ and were fixed with $70 \%$ ethanol and stored overnight at $-20^{\circ} \mathrm{C}$. The cells were centrifuged using a Heraeus Labofuge 400 centrifuge (Thermo Fisher Scientific, Waltham, MA, USA) at $300 \mathrm{x} \mathrm{g}$ and washed twice with PBS. They were labeled with $50 \mathrm{mg} / \mathrm{ml}$ PI and protected from light for $30 \mathrm{~min}$ prior to analyses by flow cytometry that were conducted with a multi-cycle system software package (CellQuest version 3.1; Beckman Coulter, Inc., Brea, CA, USA). Experiments were performed in triplicate.

Apoptosis measurement. Apoptosis was measured by $\mathrm{PI} / \mathrm{Annexin} \mathrm{V}$ double and Hoechst staining. The experimental groups were the control, radiation and the PSI + radiation groups. The radiation group received a 2-Gy treatment and the PSI + radiation group received a 2-Gy and PSI treatment using a concentration that was $20 \%$ of the $\mathrm{IC}_{50}$. The cells were harvested at $24 \mathrm{~h}$ following treatment and stained with PI and Annexin V. The apoptotic fraction was detected by flow cytometry (BD FACSCalibur; BD Biosciences, Franklin Lakes, NJ, US). The cells were washed in PBS, stained with Hoechst $33528(5 \mu \mathrm{g} / \mathrm{ml}$ in PBS) for $15 \mathrm{~min}$ at room temperature and observed under a fluorescence microscope (Olympus BX-60, Olympus Optical Co., Ltd., Tokyo, Japan) equipped with 356-nm excitation and 492-nm emission band-pass filters.

Western blot analysis. The cells were exposed to a PSI treatment of $20 \%$ of the $\mathrm{IC}_{50}$ for $3 \mathrm{~h}$ and subsequently irradiated at a dose of $2 \mathrm{~Gy}$ and incubated for $24 \mathrm{~h}$. Total cell lysates were separated by sodium dodecyl sulfate-polyacrylamide gel electrophoresis and transferred to a polyvinylidene fluoride membrane (Seebio Biotech, Inc., Shanghai, China). The membranes were incubated overnight with primary antibodies [1:1,000; caspase- 3 mouse monoclonal antibody (mAb), Bax rabbit $\mathrm{mAb}, \mathrm{Bcl}-2$ rabbit $\mathrm{mAb}$ and $\mathrm{p} 21 \mathrm{Waf1} / \mathrm{Clip1}$ rabbit $\mathrm{mAb}$ ] at $4^{\circ} \mathrm{C}$ with gentle agitation (Wave-SI slim shaker; TAITEC Corporation, Koshigaya, Japan). The membranes were incubated for $2 \mathrm{~h}$ with a horseradish peroxidase-labeled secondary antibodies (1:2,000; affinity purified goat antimouse IgG and goat antirabbit $\operatorname{IgG}$ ) at room temperature. All membranes were detected using the ECL system (Santa Cruz Biotechnology Inc.). 
Table I. Parameters of multi-target click mathematical model.

\begin{tabular}{lccccc}
\hline Group & $\mathrm{D}_{0}$ & $\mathrm{Dq}$ & $\mathrm{N}$ & $\mathrm{SF} 2(\%)$ & $\mathrm{SER}_{0}$ \\
\hline Radiation & 0.5105 & 0.1636 & 1.3777 & 37.23 & - \\
PSI + radiation & 0.2887 & 0.0598 & 1.2302 & 17.43 & 1.77 \\
\hline
\end{tabular}

$\mathrm{D}_{0}$, average lethal dosage of cells; Dq, quasi-field dosage; $\mathrm{N}$, extrapolation number; SF2, survival fraction 2; SER, sensitization enhancement ratio; PSI, Paris saponin I.

Table II. Effect of PSI on the G2/M phase of irradiated PC-9-ZD cells.

\begin{tabular}{lrrr}
\hline & \multicolumn{3}{c}{ Cell density $(\%$, mean \pm standard deviation $)$} \\
\cline { 2 - 4 } Group & \multicolumn{1}{c}{$12 \mathrm{~h}$} & \multicolumn{1}{c}{$24 \mathrm{~h}$} & $48 \mathrm{~h}$ \\
\hline Control & $7.18 \pm 1.44$ & $9.45 \pm 2.51$ & $10.89 \pm 2.72$ \\
Radiation $^{\mathrm{a}}$ & $16.56 \pm 1.35$ & $21.67 \pm 2.25$ & $24.07 \pm 2.47$ \\
PSI + radiation $^{\mathrm{b}, \mathrm{c}}$ & $27.63 \pm 2.16$ & $35.88 \pm 2.14$ & $39.30 \pm 2.53$
\end{tabular}

${ }^{\mathrm{a}} \mathrm{P}<0.05$ vs. control group; ${ }^{\mathrm{b}} \mathrm{P}<0.01$ vs. control group; ${ }^{\mathrm{C}}<0.01$ vs. radiation group. PSI, Paris saponin I.

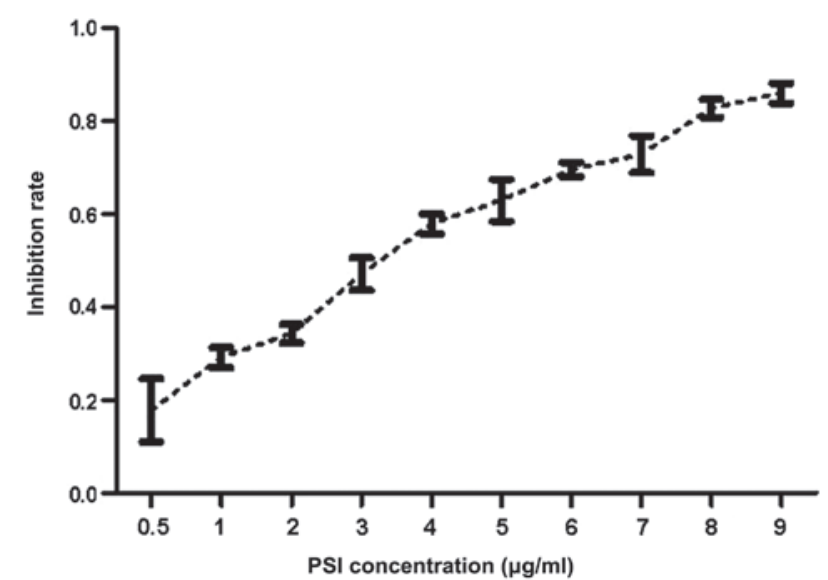

Figure 2. Inhibition rate of PSI on the PC-9-ZD cells. Percentage of cell viability was determined by MTT assay. PSI, Paris saponin I.

Statistical analysis. The t-test (mean comparison in two samples) and single-factor variance analysis (mean comparison in multiple samples) were assessed using SPSS 17.0 (SPSS, Inc., Chicago, IL, USA) and experimental data are indicated by the mean \pm SD $\mathrm{P}<0.05$ was considered to indicate a statistically significant difference.

\section{Results}

PSI inhibits the proliferation of PC-9-ZD cells. The MTT assay (Fig. 2) showed that PSI treatment inhibited cell proliferation in a dose-dependent manner. The concentration required to achieve $\mathrm{IC}_{50}$ was estimated to be $2.5132 \mu \mathrm{g} / \mathrm{ml}$ at $24 \mathrm{~h}$.

PSI enhances the radiosensitivity of PC-9-ZD cells. $0.5 \mu \mathrm{g} / \mathrm{ml}$ $\mathrm{PSI}$ and $20 \%$ of the $\mathrm{IC}_{50}$ served as the experiment concentration. A multi-target click mathematical model (Fig. 3) simulated the

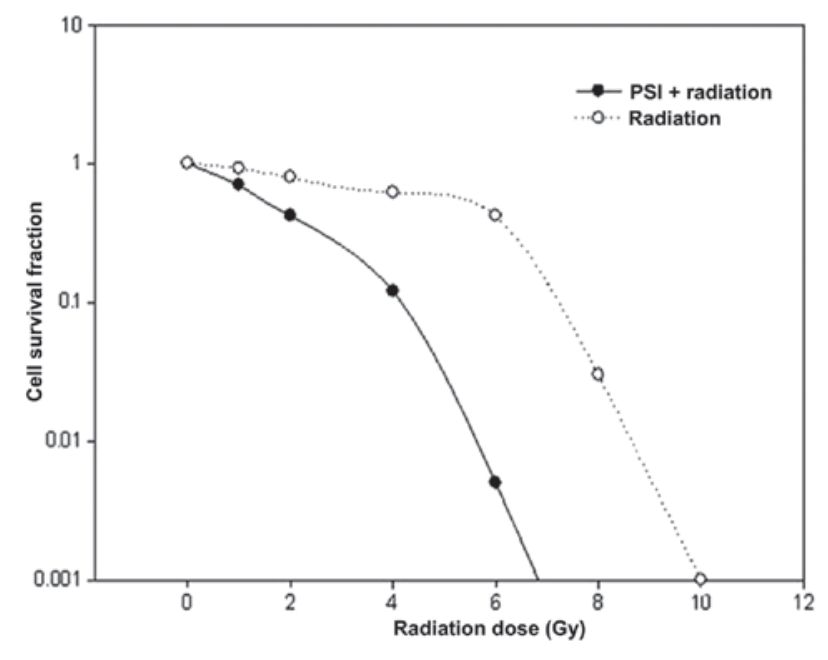

Figure 3. Clonogenic survival of PC-9-ZD cells. The cells treated with or without $0.5 \mu \mathrm{g} / \mathrm{ml}$ PSI were exposed to X-ray irradiation; range, $0-10 \mathrm{~Gy}$. Subsequently, cells were incubated for 14 days and the number of colonies with $>50$ cells was scored. PSI, Paris saponin I.

cell SF curve, through which an associated equation and radioactivity parameters, $\mathrm{D}_{0}$ and $\mathrm{Dq}$ (Table $\mathrm{I}$ ) were obtained. The results show a declined SF2, a decreased Dq and the shoulder of the survival curve is decreased, with an SER value of 1.77 , based on $\mathrm{D}_{0}$.

PSI induces the G2/M arrest of irradiated PC-9-ZD cells. To identify whether the radiosensitivity of PSI was due to cell cycle arrest, the influence of PSI treatment $(0.5 \mu \mathrm{g} / \mathrm{ml} ; 20 \%$ of $\mathrm{IC}_{50}$ ) on cell cycle distribution was observed (Table II). The result showed that irradiation alone induced $\mathrm{G} 2 / \mathrm{M}$ arrest in a time-dependent manner with an increased cell density at the G2/M phase from 16.56 to $24.07 \%$ compared with the control group $(\mathrm{P}<0.05)$. However, PSI altered the cycle distribution of 
A

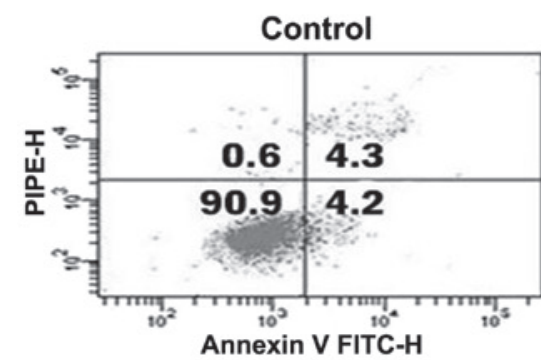

B

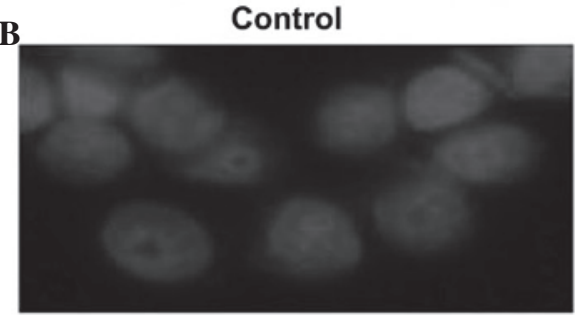

Radiation

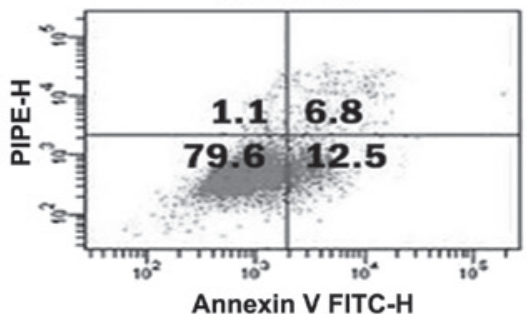

Radiation

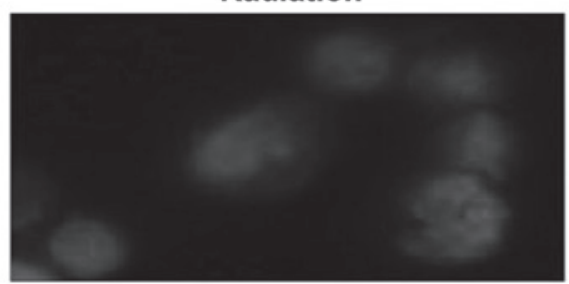

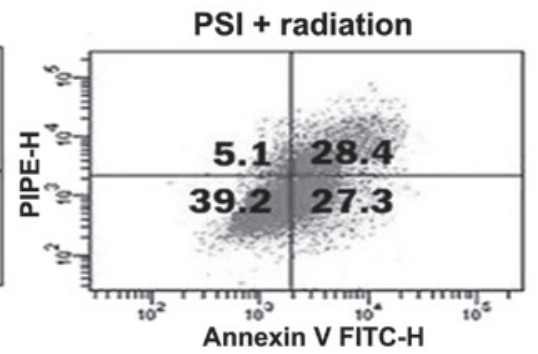

PSI + radiation

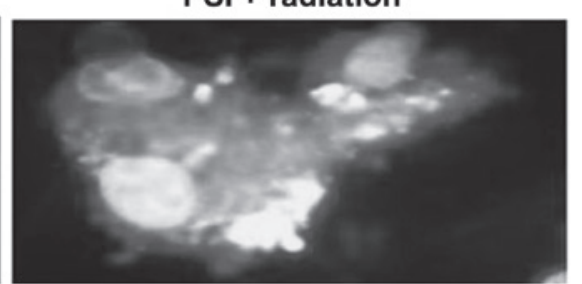

Figure 4. (A) PSI on the apoptosis of irradiated PC-9-ZD cells. The experimental groups were the control, radiation and PSI + radiation groups. The radiation group received 2-Gy treatment and the PSI + radiation group received 2-Gy and a PSI treatment of $20 \%$ of the $\mathrm{IC}_{50}$. Cells were harvested at $24 \mathrm{~h}$ following treatment and stained with propidium iodide and Annexin V. The apoptotic fraction was detected by flow cytometry. (B) Fluorescence imaging of the nuclei in the control, radiation and PSI + radiation groups by Hoechst 33258 staining. PC-9-ZD cells stained with Hoechst 33528 were visualized by fluorescence microscopy. Condensed and fragmented nuclei were observed in the PSI + radiation group, but not in the control and radiation groups. PSI, Paris saponin I.

irradiated cells significantly, leading to cell cycle arrest at the $\mathrm{G} 2 / \mathrm{M}$ phase in a time-dependent manner with an increased cell density at the G2/M phase from 27.63 to $39.30 \%$ compared with the radiation group $(\mathrm{P}<0.01)$.

PSI induces apoptosis of irradiated PC-9-ZD cells. In order to investigate the radiosensitivity mechanism of PSI, the influence of PSI $\left(0.5 \mu \mathrm{g} / \mathrm{ml} ; 20 \%\right.$ of $\left.\mathrm{IC}_{50}\right)$ on cell apoptosis was observed by Annexin V/PI double and Hoechst staining assays. Irradiation increased apoptosis at $24 \mathrm{~h}$, however, the PSI combination treatment further increased the apoptosis ratio up to the higher level ( $\mathrm{P}<0.01$; Fig. 4A). Fig. 4B demonstrates that the control and irradiated cells were morphologically normal, and the nuclei were regularly shaped and evenly stained. However, typical morphological changes of apoptosis, including nuclear shrinkage, DNA condensation and chromatin fragmentation were identified in the PSI + radiation group. This indicates that PSI treatment can further increase apoptosis that is induced by radioactive rays.

PSI upregulates $P 21^{\text {wafl/cipl }}$, caspase-3 and Bax, and downregulates $B c l-2$ protein expression of irradiated $P C-9-Z D$ cells. In order to confirm which modulating molecules were involved in the PSI treatment on cell cycle arrest and apoptosis of irradiated PC-9-ZD cells, P21 $1^{\text {waf } 1 / \text { cip } 1}$, the most significant regulator in the cell cycle checkpoint, and caspase-3, Bax and Bcl-2, which are significant apoptosis regulators, were investigated. The results showed that PSI significantly increased the expression of $\mathrm{P} 21^{\text {waf } 1 / \text { cip } 1}$, caspase- 3 and Bax in irradiated PC-9-ZD cells. Notably, PSI markedly decreased Bcl-2 expression in the irradiated cells (Fig. 5). This incidates that increased $\mathrm{P} 21^{\mathrm{waf} 1 / \mathrm{cip} 1}$ expression contributes to $\mathrm{G} 2 / \mathrm{M}$ arrest, and increased caspase- 3 and Bax expression levels; however, a decreased $\mathrm{Bcl}-2$ expression contributes to apoptosis, which is induced by PSI treatment in irradiated cells.
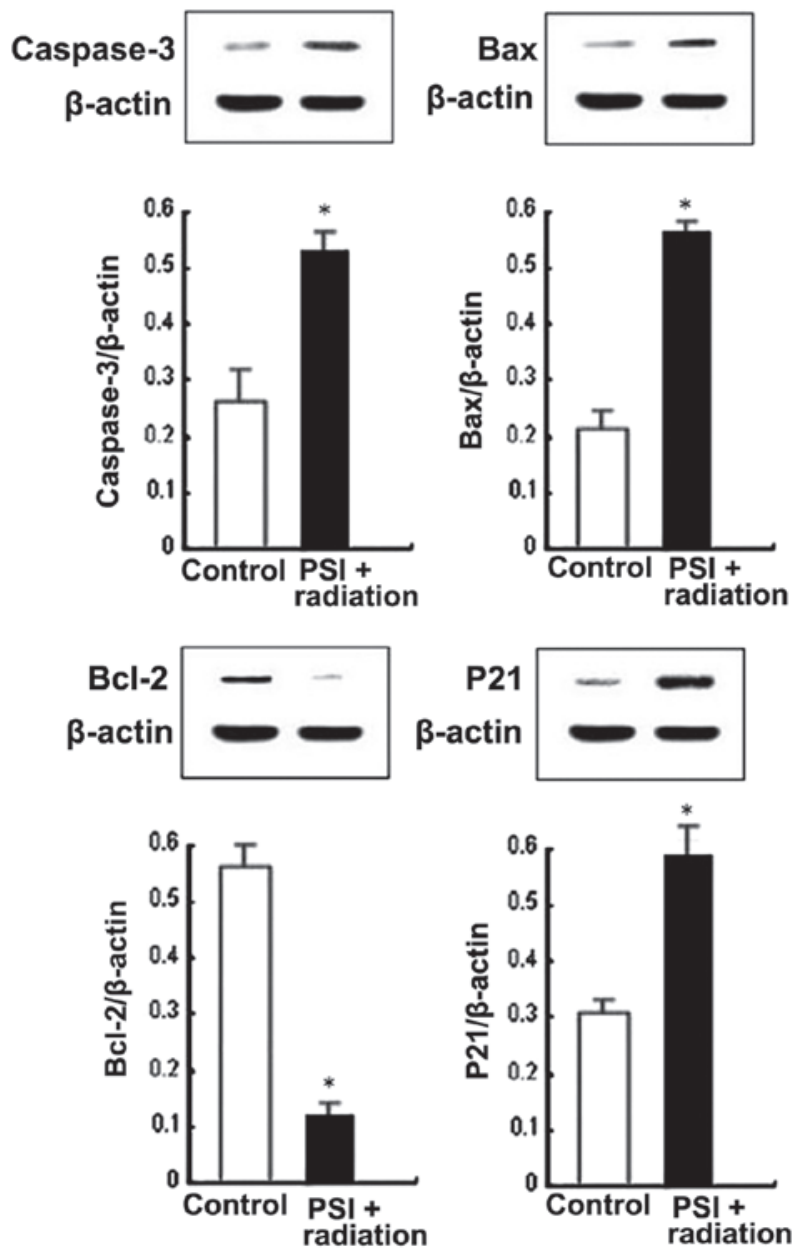

Figure 5. PSI significantly increases the expression of $\mathrm{P} 21^{\text {waf } 1 / \text { cip } 1}$, caspase- 3 and Bax, however, decreases the expression of Bcl-2 of the irradiated PC-9-ZD cells. $\beta$-actin expression served as an internal control. Values are the means of triplicate analysis and error bars show standard deviations. ${ }^{*} \mathrm{P}<0.05$ vs. control group. Bax, Bcl-2-like protein 4; PSI, Paris saponin I; Bcl-2, B-cell lymphoma 2; P21 $1^{\text {waf1/cipl }}$, cyclin-dependent kinase inhibitor 1. 


\section{Discussion}

In the present study, simulating the comparison for the irradiation-survival curve of PC-9-ZD cells using a multi-target click mathematical model formula reveals that the $\mathrm{D}_{0}$, Dq and $\mathrm{N}$ values of cells is decreased following a PSI treatment of irradiated cells. PSI enhances the radiosensitivity effect of PC-9-ZD cells with an SER of 1.77. These results indicate that, following treatment with PSI, the average lethal dosage of the PSI + radiation group is decreased compared with the control group, the shoulder is clearly decreased, and the repair ability of cell sublethal injury is markedly decreased. The radiosensitivity effect of PSI treatment is evidently increased in the PC-9-ZD cells, the average lethal dosage is decreased with irradiation, the decrease of shoulder is more significant and the repair ability of cell sublethal injury is clearly decreased.

Further studies have been conducted to investigate the radiosensitivity mechanism of PSI treatment. The results from assessing the cell cycle and apoptosis in the present study indicate that PSI predominantly induces G2/M phase arrest and apoptosis. Apoptosis was the primary reason for cell death induced by PSI in the irradiated cells. It was shown that a PSI combination treatment advanced the apoptosis ratio up to a higher level. In addition, PSI further increases apoptosis that is induced by radioactive rays. Caspases are essential mediators of apoptosis. Among them, caspase-3 is a frequently activated death protease, catalyzing the specific cleavage of numerous key cellular proteins (19). The Bcl-2 family, which comprises of anti-apoptotic (including Bcl-2 and Bcl-xl) and proapoptotic (including Bax and Bak) members, is the predominant controller and mediator of cell apoptosis $(20,21)$. Particularly, the high Bcl-2/Bax ratio is considered to be a crucial factor of cell resistance to apoptosis $(22,23)$. To investigate the role of PSI in the irradiation-induced apoptosis pathway in gefitinib-resistant PC-9-ZD cells, the Bcl-2 family proteins and the caspase- 3 protein were analyzed in the present study. The results indicated that Bcl-2 was decreased, and Bax and caspase- 3 were increased as a result of PSI treatment. Thus, PSI promotes the irradiation-induced apoptosis via the association between Bcl-2 and Bax, and caspase-3, eventually leading to enhanced radiosensitivity.

Furthermore cell cycle arrest was the major reason for cell death, which was induced by PSI in the irradiated cells. Cell cycle regulation was significant for cell proliferation and the cells exhibited varied radiosensitivity in various phases of the cell cycle. Cells were most sensitive to irradiation during the G2/M phase, less sensitive during G1, and least sensitive near the end of the $S$ phase (24). It was shown in the present study that PSI treatment significantly altered the cycle distribution of the irradiated cells, leading to cell cycle arrest at the $\mathrm{G} 2 / \mathrm{M}$ phase in a time-dependent manner, with an increased cell density at the $\mathrm{G} 2 / \mathrm{M}$ phase from 27.63 to $39.30 \%$. Previously, P21 ${ }^{\text {waf1/cipl }}$ was considered to be the most significant cell cycle checkpoint protein (25-27). In the present study it was shown that PSI significantly increased the expression of $\mathrm{P} 21^{\text {waf1/cipl }}$, which resulted in cell-cycle progression via $\mathrm{G} 2 / \mathrm{M}$ arrest in the PC-9-ZD cells. This indicates that P21 $1^{\text {waf } 1 / \text { cip1 }}$ is significant in mediating cell growth through $\mathrm{G} 2 / \mathrm{M}$ arrest in gefitinib-resistant cell lines.
In conclusion, PSI exhibited potent radiosensitivity against gefitinib-resistant PC-9-ZD cells in vitro. This radiosensitivity was associated with the cell cycle arrest at the $\mathrm{G} 2 / \mathrm{M}$ phase and apoptosis via increased caspase-3, Bax and P21 $1^{\text {waf } 1 / \text { cip1 }}$ and decreased $\mathrm{Bcl}-2$ production. Therefore, PSI may have the potential to be a radiosensitizer, however, this requires further investigation.

\section{Acknowledgements}

The present study was supported by grants from the National Natural Science Foundation of China (grant no. 81303274), Wujieping Foundation of China (grant no.320.6700.09035)and Zhejiang traditional medicine Project (grant no. 2011ZZ011).

\section{References}

1. Sordella R, Bell DW, Haber DA and Settleman J: Gefitinib sensitizing EGFR mutations in lung cancer activate anti-apoptotic pathways. Science 305: 1163-1167, 2004.

2. Workman P: Altered states: selectively drugging the Hsp90 cancer chaperone. Trends Mol Med 10: 47-51, 2004.

3. Kobayashi N, Toyooka S, Soh J, et al: The anti-proliferative effect of heat shock protein 90 inhibitor, 17-DMAG, on non-small-cell lung cancers being resistant to EGFR tyrosine kinase inhibitor. Lung Cancer 75: 161-166, 2012.

4. Jackman DM, Yeap BY, Sequist LV, et al: Exon 19 deletion mutations of epidermal growth factor receptor are associated with prolonged survival in non-small cell lung cancer patients treated with gefitinib or erlotinib. Clin Cancer Res 12: 3908-3914, 2006.

5. Riely GJ, Pao W, Pham D, et al: Clinical course of patients with non-small cell lung cancer and epidermal growth factor receptor exon 19 and exon 21 mutations treated with gefitinib or erlotinib. Clin Cancer Res 12: 839-844, 2006.

6. Giaccone G: Clinical impact of novel treatment strategies. Oncogene 21: 6970-6981, 2002.

7. Grabley $\mathrm{S}$ and Thiericke R: Bioactive agents from natural sources: trends in discovery and application. Adv Biochem Eng Biotechnol 64: 101-154, 1999.

8. Wang Y, Zhang YJ, Gao WY and Yan LL: Anti-tumor constituents from Paris polyphylla var. yunnanensis. Zhongguo Zhong Yao Za Zhi 32: 1425-1428, 2007 (In Chinese).

9. Sun J, Liu BR, Hu WJ, et al: In vitro anticancer activity of aqueous extracts and ethanol extracts of fifteen traditional Chinese medicines on human digestive tumor cell lines. Phytother Res 21: 1102-1104, 2007.

10. Lee MS, Yuet-Wa JC, Kong SK, et al: Effects of polyphyllin $\mathrm{D}$, a steroidal saponin in Paris polyphylla, in growth inhibition of human breast cancer cells and in xenograft. Cancer Biol Ther 4: 1248-1254, 2005.

11. Cheung JY, Ong RC, Suen YK, et al: Polyphyllin D is a potent apoptosis inducer in drug-resistant HepG2 cells. Cancer Lett 217: 203-211, 2005.

12. Siu FM, Ma DL, Cheung YW, et al: Proteomic and transcriptomic study on the action of a cytotoxic saponin (Polyphyllin D): induction of endoplasmic reticulum stress and mitochondria-mediated apoptotic pathways. Proteomics 8: 3105-3117, 2008.

13. Jiang H, Su D and Ma SL: The effect of Chonglou Saponin I on proliferation and apoptosis in lung adenocarcinoma cell line PC9. J Chinese Oncol 18: 166-169, 2012.

14. Hua YH, Ma SL, Fu ZF, et al: Effect of Polyphyllin I on radiosensitivity in nasopharyngeal carcinoma cell line CNE-2 in vitro. Chinese Archives of Traditional Chinese Medicine 29: 1387-1390, 2011 (In Chinese).

15. Xiao M, Dai X, He X, et al: Paris saponin I induces $G_{2} / M$ cell cycle arrest and apoptosis in human gastric carcinoma SGC7901 cells. J Huazhong Univ Sci Technol Med Sci 31: 768-772, 2011.

16. Xiao X, Bai P, Bui Nguyen TM, et al: The antitumoral effect of Paris Saponin I associated with the induction of apoptosis through the mitochondrial pathway. Mol Cancer Ther 8: 1179-1188, 2009.

17. Yan LL, Zhang YJ, Gao WY, et al: In vitro and in vivo anticancer activity of steroid saponins of Paris polyphylla var. yunnanensis. Exp Oncol 31: 27-32, 2009. 
18. Ji Y, Ma SL, Zhang YP, et al: Combined treatment with TNF-alpha/gefitinib alleviates the resistance to gefitinib in PC-9 cells. Anticancer Drugs 20: 832-837, 2009.

19. Porter AG and Jänicke RU: Emerging roles of caspase-3 in apoptosis. Cell Death Differ 6: 99-104, 1999.

20. Hengartner MO: The biochemistry of apoptosis. Nature 407: 770-776, 2000.

21. Shroff EH, Snyder C and Chandel NS: Bcl-2 family members regulate anoxia-induced cell death. Antioxid Redox Signal 9: 1405-1409, 2007.

22. Reed JC, Miyashita T, Takayama S, et al: BCL-2 family proteins: regulators of cell death involved in the pathogenesis of cancer and resistance to therapy. J Cell Biochem 60: 23-32, 1996.

23. Sedlak TW, Oltvai ZN, Yang E, et al: Multiple Bcl-2 family members demonstrate selective dimerizations with Bax. Proc Natl Acad Sci USA 92: 7834-7838, 1995.
24. Zha L, Qiao T, Yuan S, et al: Enhancement of radiosensitivity by CpG-oligodeoxyribonucleotide-7909 in human non-small cell lung cancer A549 cells. Cancer Biother Radiopharm 25: 165-170, 2010.

25. Ma S, Tang J, Feng J, et al: Induction of p21 by p65 in p53 null cells treated with Doxorubicin. Biochim Biophys Acta 1783: 935-940, 2008.

26. Tang JJ, Shen C and Lu YJ: Requirement for pre-existing of $\mathrm{p} 21$ to prevent doxorubicin-induced apoptosis through inhibition of caspase-3 activation. Mol Cell Biochem 291: 139-144, 2006.

27. Xiao GH, Beeser A, Chernoff J and Testa JR: p21-activated kinase links Rac/Cdc42 signaling to merlin. J Biol Chem 277: 883-886, 2002. 